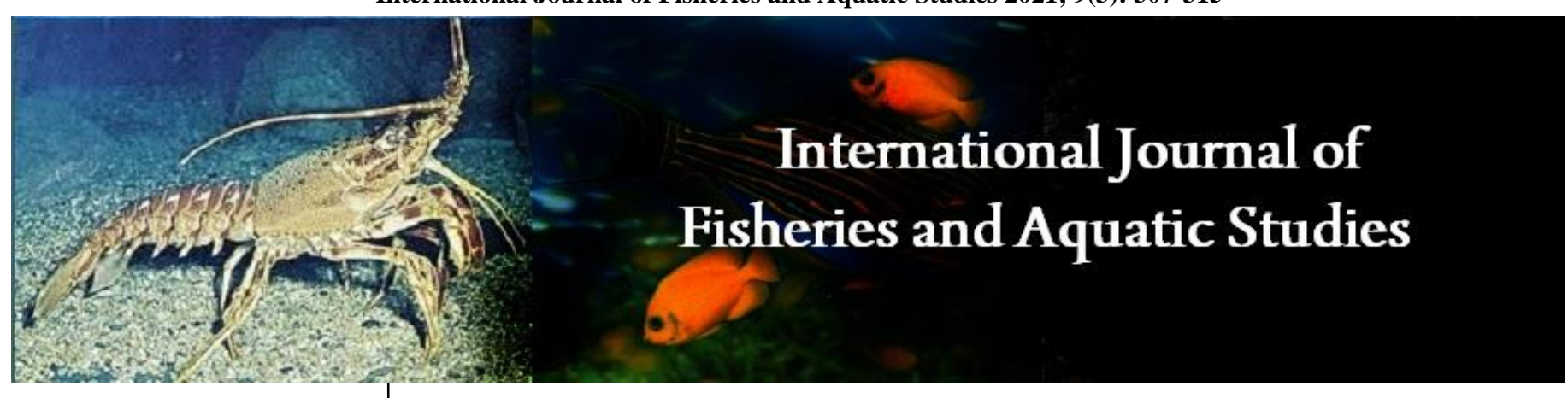

E-ISSN: 2347-5129

P-ISSN: 2394-0506

(ICV-Poland) Impact Value: 5.62

(GIF) Impact Factor: 0.549

IJFAS 2021; 9(3): 307-315

(C) 2021 IJFAS

www.fisheriesjournal.com

Received: 28-03-2021

Accepted: 30-04-2021

S Selvaraj

Department of Aquaculture,

Dr. M.G.R. Fisheries College and Research Institute, Tamil Nadu

Dr. J. Jayalalithaa Fisheries

University, T.H. Road, Ponneri,

Thiruvallur, Tamil Nadu, India

\section{B Ahilan}

Department of Aquaculture,

Dr. M.G.R. Fisheries College and

Research Institute, Tamil Nadu

Dr. J. Jayalalithaa Fisheries

University, T.H. Road, Ponneri,

Thiruvallur, Tamil Nadu, India

Corresponding Author:

S Selvaraj

Department of Aquaculture,

Dr. M.G.R. Fisheries College and

Research Institute, Tamil Nadu

Dr. J. Jayalalithaa Fisheries

University, T.H. Road, Ponneri,

Thiruvallur, Tamil Nadu, India

\section{A mini-review on kisspeptin hormone as an inducing agent in fish breeding}

\section{S Selvaraj and B Ahilan}

DOI: https://doi.org/10.22271/fish.2021.v9.i3d.2506

\section{Abstract}

Kisspeptin system is involved in the control of reproduction in vertebrates, including teleost fish. Neuroanatomical distribution of kisspeptin neurons has confirmed their distribution in the preoptic area and hypothalamus of several teleost fish. In few species including chub mackerel, kisspeptin system has been shown to stimulate GnRH neurons in regulating the reproductive processes. Expression changes of kiss and gnrh mRNAs in teleost fish have demonstrated increased expression during the reproductive cycle. Interestingly, like mammalian species kisspeptin mediates the positive feedback effect of sex steroids in sexually mature fish including medaka and goldfish. In several teleosts, pharmacological administration of synthetic kisspeptin peptides affects gene expression of $g n r h l, f \operatorname{sh} \beta$ and $\operatorname{lh} \beta$, and also induces gonadal development in immature fish, suggesting their possible application in captive reproduction. This review highlights the importance of selection of suitable mature peptides of fish kisseptins for induced maturation in captivity.

Keywords: kisspeptins, Kiss1, Kiss2, reproduction, teleosts

\section{Introduction}

Kisspeptin system are considered as gatekeeper of reproductive function, including sexual differentiation, puberty onset, seasonal gonadal development, maturation and spawning in various vertebrate species (Gottsch et al., 2004; Castellano et al., 2009; Pasquier et al., 2014; Cao et al., 2019; Feng et al., 2019) ${ }^{[16,6,54,5,13]}$. In placental mammals, the kisspeptin is encoded by a single Kiss 1 gene; however, in teleosts encoded by two kiss genes, kissl and kiss 2 with the exception of puffer fish, Senegalese sole, three spined stickleback (Akazome et al., 2010; Mechaly et al., 2009, 2011; Nagler et al., 2011; Somoza et al., 2020) [1, 34, 35, 40, 72]. Also, in red seabream, a premature stop codon was present upstream of kisspeptin-10 region (Shimizu et al., 2012) ${ }^{[69]}$. In contrast to the situation in mammals where the anatomy and physiology of kisspeptin systems are well understood, studies in non-mammalian vertebrates particularly teleosts, where species differences have been observed, making the kisspeptin system more complex in fish reproductive physiology (Alvarado et al., 2016; Somoza et al., 2020) ${ }^{[2,72]}$.

Before kisspeptins demonstration on significant involvement in the reproductive function, gonadotropin-releasing hormone $(\mathrm{GnRH})$ was thought to be the upstream modulator of the brain-pituitary-gonad (BPG) axis (Kah et al., 2007; Kauffman et al., 2007) ${ }^{[17,23]}$. Kisspeptins act through kisspeptin receptor, primarily expressed by preoptic and hypothalamic GnRH neurons (Lee et al., 2009; Um et al., 2010; Akazome et al., 2010; Matsuyama et al., 2013; Zhao et al., 2014) ${ }^{[29,76,1,32,82]}$. These GnRH neurons regulate the synthesis and secretion of pituitary gonadotropins ( $\mathrm{GtHs}$ ), follicle stimulating hormone (FSH) and luteinizing hormone (LH). Pituitary GtHs, in turn stimulate the production of sex steroids, responsible for the progression of gonadal growth and maturation (Yaron et al., 2003) ${ }^{[80]}$. In mammals, KISS1 precursor protein is shown to be proteotically cleaved into several mature peptides, including KISS-54, -14, -13 and -10 (Kotani et al., 2001; Gottsch et al., 2004) ${ }^{[27,16]}$. All these peptides possess a distinct structural Arg-Phe-amide motif in their C-terminus and are shown to activate kisspeptin receptor with equal biopotency. In teleosts, multiple mature peptides have been reported in recent years (Ohga et al., 2020) ${ }^{[46]}$. 


\section{Neuroanatomical Distribution of Kisspeptin Neurons}

Using in-situ hybridization, several studies have demonstrated the kiss 1 and kiss 2 expressing cells in the brain of teleost fish (Ogawa et al., 2013) ${ }^{[43]}$. In the adult zebrafish brain, kissl cells are exclusively localized in the ventromedial habenula and the periventricular hypothalamic nucleus. The kiss2 mRNA was observed in the preoptic area (POA), mediobasal hypothalamus, posterior tuberal nucleus and the periventricular hypothalamic nucleus (Kitahashi et al., 2009; Servilli et al., 2011) ${ }^{[26,63]}$. In the mature medaka, distribution of kiss1 expressing cells was restricted to habenula and hypothamic regions, nucleus ventral tuberis (NVT) and nucleus posterioris periventricularis (NPPv). NVT kissl neurons in medaka exhibit sexual dimorphism, with male neurons being more than female ones (Kanda et al., 2008) ${ }^{[18]}$. In the medaka, kiss 2 expressing cells are localized in the similar regions as that of zebrafish (Mitani et al., 2010) ${ }^{[38]}$. Like zebrafish, kiss 1 expression was recorded in the habenula and hypothalamic regions, and kiss 2 expression in the POA, nucleus lateralis tuberis (NLT) and nucleus recessus lateralis (NRL) of goldfish (Kanda et al., 2012) ${ }^{[20,21]}$. In the striped bass, neurons expressing kiss 1 are found to be dorsal (NRLd) and ventral (NRLv) subdivisions of the lateral nucleus of the recess, and the posterior tuberal nucleus (NPT) of the hypothalamus. The kiss 2 expression was found in the similar regions of kissl expression, NRLd and NRLv (Zmora et al., 2012) ${ }^{[83]}$. In the European seabass, kiss 1 expressing cells are found in the habenula and rostral mediobasal hypothalamus, with kiss2 distribution in the preoptic area and dorsal hypothalamus, above and under the lateral recess (Escobar et al., 2013) ${ }^{\text {[9] }}$. The kiss1- and kiss2-expressing neurons were mainly localized in the NRL and the nucleus of the posterior recess (NRP) in the hypothalamus of chub mackerel (Ohga et al., 2017) ${ }^{[51]}$. In the red seabream expressing only kiss2, neurons that express kiss2 are distributed in the dorsal (NRLd) and ventral (NRLv) parts of nucleus recessi lateralis in the hypothalamus (Shimizu et al., 2012) ${ }^{[69]}$. In this study, the authors found that number of kiss 2 expressing neurons in the NRLd was larger during the spawning season in both males and females, compared to post-spawning fish. Similarly, the number of kiss 2 neurons in NRLd of maturing male was higher than post-spawning male. The kiss 2 mRNA expressing cells are localized in the nucleus of lateral recess in the hypothalamus of Nile tilapia (Ogawa et al., 2013) ${ }^{[42] .}$

Using immunocytochemisty, it was confirmed that kiss1 producing neurons are only localized in the habenular nucleus and project to the interpeduncular and raphe nuclei. In contrast, kiss 2 producing neurons are mostly present in the dorsal and ventral hypothalamus and project widely into the subpallium, preoptic area, thalamus, ventral and caudal hypothalamus and the mesencephalon (Servili et al., 2011) [63]. Similarly, in the European seabass, using specific antibodies raised against preprokiss2, it was found that kiss2 neurons are mainly located in the hypothalamus and project widely to the subpallium and pallium, preoptic area, thalamus, pretectal area, optic tectum, mediobasal medial and caudal hypothalamus and the neurohypophysis (Escobar et al., 2013) [9]. In the striped bass, kiss1- and kiss2-immunoreactive neurons were localized in the NLT and innervated the neurohypophysis, suggesting direct regulation of $\mathrm{GnRH}$ in this species (Zmora et al., 2013) ${ }^{[83]}$.

\section{GnRH Neurons Express Kissspeptin Receptors}

Parhar et al. (2004) first demonstrated the co-localization of kisspeptin receptor mRNA with the three gnrh mRNAs in the Nile tilapia brain. Later, it was confirmed that expression of kissr mRNA peaks during puberty in cobia and grey mullet (Mohamed et al., 2007; Nocillado et al., 2007) [41]. Furthermore, Khan et al. (2008) confirmed that kissr protein colocalized with multiple GnRh forms in Atlantic croaker. In the African cichlid fish, kiss $1 r$ was localized in the GnRH1 and GnRH3 neurons (Grone et al., 2010) ${ }^{[14]}$. Using antibodies raised against the $\mathrm{C}$-terminus of zebrafish preproKiss1 and preproKiss2, only Kiss2 fibers profusely innervated the ventral forebrain and notably made close apposition with GnRH neurons, suggesting direction regulation of kisspeptin on GnRH in zebrafish (Servili et al., 2011) ${ }^{[63]}$. In contrast, in the medaka kisspeptin receptors did not co-localized in $\mathrm{GnRH}$ neurons, suggesting indirect regulation in this species. In this species, kisspeptin receptors are expressed in POA surrounding the Gnrh neurons, and the study found that isotocin and vasotocin neurons in POA express kisspeptin receptors (Kanda et al., 2013) ${ }^{[19]}$. Similarly, in the European seabass and Nile tilapia, Gnrh1 neurons did not appear to express kisspeptin receptors (Escobar et al., 2013; Ogawa et al., 2013) ${ }^{[9,42]}$. The kissr2 expressing neurons are tyrosine hydroxylase, neuropeptide $\mathrm{Y}$ and neuronal nitric oxide producing neurons, suggesting indirect regulation of kisspeptin on Gnrh (Escobar et al., 2013) ${ }^{[8,9]}$. In the striped bass, kissr2 was colocalized in POA Gnrh1 neurons (Zmora et al., 2012) ${ }^{[83]}$. Using immunocytochemistry in the striped bass, it was confirmed that kiss1-immunoreactive neurons directly innervate into pituitary regions where luteinizing hormone producing cells are localized. Further, kiss2 innervations were prominent in the NLT region and the neurohypophysis, forming large axonal bundles and intermingling with Gnrh1 axons, suggesting direction regulation of kisspeptin to Gnrh in this species. Espigares et al. (2015) indicated that the forebrain-midbrain acts as functional endocrine signaling pathway of kiss $2 / \mathrm{Gnrh} 1$ system controlling the gonadotroph activity in the European seabass and kiss2 is a potent regulator of pituitary Fsh and Lh secretion via paracrine/autocrine signaling. Similarly, in the chub mackerel POA, GnRh neuron coexpresses kissrl, suggesting kisspeptins direct regulation on $\mathrm{GnRh}$ in this

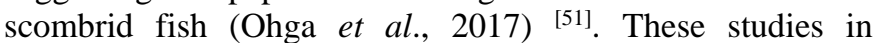
different species clearly indicate that kisspeptin may regulate directly or indirectly GnRH neurons to modulate reproductive events.

\section{Kisspeptin Neurons Express Estrogen Receptors}

Gonadal sex steroids have been identified as important regulators of preoptic and hypothalamic kisspeptin systems. Double label insitu hybridization found that medaka NVT kiss1 neurons coexpress estrogen-receptor- $\alpha(\mathrm{ER} \alpha)$, whereas NRL kiss2 neurons do not. The study found that kiss1 neurons in the NVT decreased after ovariectomy, and recovered after estrogen treatment (Kanda et al., 2008) ${ }^{[18] .}$ The authors concluded that NVT kiss 1 neurons are positively regulated by ovarian estrogen via their coexpressed ER $\alpha$ and are directly involved in the central regulation of reproduction in medaka (Kanda et al., 2008; Mitani et al., 2010) ${ }^{[18,38] .}$ Estrogen treatment of juvenile zebrafish with estradiol caused an increase in kiss 1 and kiss 2 expression, particularly at the periphery of the anterior tuberal nucleus and in the caudal hypothalamus (Servili et al., 2011) ${ }^{[63]}$. In the goldfish, upregulation of gene expression by ovarian steroids was observed only in the kiss 2 neurons of the POA, and this 
observation coincided with the expression of estrogen receptor in these kiss 2 neurons (Kanda et al., 2012; Kanda and Oka, 2012) ${ }^{[20-21]}$. The authors found that in breeding females, kiss 2 expression was significantly higher in the POA and NLT, whereas there was no significant difference between these conditions in NRL. Wang et al. (2013) demonstrated that the goldfish kisspeptin neurons co-express the estrogen receptors, with eral and erbl in the habenula kiss1 neurons and eral, era2, and erbl in the preoptic and hypothalamic kiss2 neurons. Interestingly, the study confirmed that estrogen (17 $\beta$-estradiol, $\left.\mathrm{E}_{2}\right)$ treatment enhances the promoter activities of two kiss genes in the presence of $E R \alpha$, suggesting that $E_{2}$ is capable of exerting positive feedback regulation on the expression of kiss 1 and kiss2 in the goldfish. In the European seabass, most kiss1 expressing cells of the mediobasal hypothalamus strongly express ER $\alpha$ (Escobar et al., 2013) ${ }^{[8-9]}$. The study did find any coexpression of kiss 2 and ER $\alpha$ or ER $\beta 1$. In the European seabass and striped bass, mediobasal hypothalamus acts as a major site for sex steroid actions on kisspeptins in this species (Zmora et al., 2013; Alvarado et al., 2016) ${ }^{[84,2]}$. These studies clearly indicate that though species specific differences exist, the kisspeptin system is involved in mediating sex steroid regulation in teleosts.

\section{Expression Changes of Kisspeptin mRNAs During the Reproductive cycle}

In the chub mackerel, expression changes of kisspeptin and gnrh mRNAs were analyzed during different stages of reproductive periods: early development, sexual differentiation, puberty, seasonal reproductive and spawning cycles (Selvaraj et al., 2010, 2015; Ohga et al., 2013, 2015) $[58,59,45,47]$. Expression changes of kiss mRNAs during early development (0-30 dphs) and gonadal sex differentiation periods (37-60 dphs) indicated that kiss, kissr and gnrh mRNA levels were higher between 0 and $15 \mathrm{dphs,}$ in comparison to other early developmental periods. During sexual differentiation periods, kiss2, kissrl, and kissr 2 mRNA levels were higher at $37 \mathrm{dph}$, in comparison to 45 and 60 dphs. These expression profiles indicated that kisspeptin systems are involved in the early larval development and sexual differentiation of the brain of chub mackerel (Selvaraj et al., 2015) ${ }^{[59]}$. During pubertal onset in male fish, kiss2, kissrl, kissr2 levels increased significantly at 14 weeks posthatch (wph), synchronously with an increase in type A spermatogonial populations in the testis; kiss 2 and gnrhl levels significantly increased at $22 \mathrm{wph}$, just before the onset of meiosis in the testis. In female fish, kissl and kiss 2 levels increased significantly with an increase in kissrl, kissr 2 and gnrhl levels at $24 \mathrm{wph}$, just before the appearance of vitellogenic oocytes in the ovary (Ohga et al., 2015) ${ }^{[45]}$. These result clearly indicated positive involvement of kisspeptin-GnRH system in the pubertal onset in the chub mackerel. During seasonal reproductive cycle, kiss 1 levels in the males were higher during immature stage when the testis is mainly occupied with spermatogonia, and lower during post-spawning stage, when the testis was contained of residual spermatozoa. In contrast, kiss 1 levels in the females did not show any significant fluctuations; however, the mRNA levels were 2-fold higher than males at different stages analyzed (Selvaraj et al., 2010) ${ }^{[58]}$. The kiss 2 expression profiles were similar in males and females with levels higher during early gametogenic periods compared to later stages. Like kiss 1, kiss2 levels in the females were 1.5- fold higher than males, suggesting their involvement in the seasonal reproductive cycle of chub mackerel. Seasonal expression changes of kisspeptin receptors showed higher expression levels of both kissrl and kissr 2 in the brain of the females during early vitellogenic period; however, no significant differences were found in the brain of males. Increased expression of kiss 2 coincided with kissr 1 and kissr2 in female brain, suggesting their dominant involvement in the female reproductive cycle (Ohga et al, 2013) ${ }^{[47]}$. During the spawning season, both kissl and kiss2 levels were higher compared to seasonal reproductive cycle stages. Particularly, kiss 1 and kiss 2 levels were higher during the final oocyte maturation (FOM) stages, germinal vesicle migration and hydration stages compared to the late vitellogenesis in females. These peaks coincided with circulating estradiol levels in the blood plasma (Matsuyama et al., 2005; Selvaraj et al., 2012) ${ }^{[33,57]}$. Surprisingly, expression of both kisspeptin receptor genes significantly decreased during FOM, suggesting rhythmic expression of kiss/kissr during the spawning season are involved in the regulation of LH surge (Ohga et al., 2017) ${ }^{[44]}$. These studies in chub mackerel have clearly demonstrated the involvement of kisspeptin-GnRH system in the regulation of reproductive cycle (Ohga et al., 2018) ${ }^{[50]}$.

Studies in other fish species expressing two kiss genes have also indicated increased expression of elements of BPG axis including kisspeptins. Kitahashi et al. (2009) found a significant increase in zebrafish kiss1, kiss2, gnrh2, gnrh3 mRNA levels at the start of the pubertal phase and remained high in adulthood, suggesting involvement of kisspeptinGnRH systems in the regulation of pituitary gonadotropins. In this species, temperature differentially regulates the two kisspeptin systems in the brain, with kiss1/kissr1 system sensitive to low temperature and kiss $2 / \mathrm{kissr} 2$ system sensitive to high and low extremes of temperature (Shahjahan et al., 2013) [65]. In the brain of mature female striped bass, both kiss 1 and kiss 2 mRNAs, including levels of their receptors kissrl and kissr2, were found to be significantly increased in comparison to juvenile and prepubertal fish (Zmora et al., 2012) ${ }^{[83]}$. Both kissl and kiss 2 mRNAs were detectable at 1 day post fertilization (dpf) and then increased during the first week of life (Zhao et al., 2014) ${ }^{[82]}$. In Indian major carp, rohu, kiss1 and kiss2 expression was elevated during prespawning and spawning periods (Saha et al., 2016) [56]. In pejerrey, all members of the kisspeptin system are expressed during early period, and the increase of kiss 2 transcripts at week 4 suggested as their involvement in the differentiation of the brain-pituitary axis in male development (Bohórquez et al., 2017) ${ }^{[2]}$. In the golden mahseer, expression of kiss 1 and kissr mRNAs was comparatively higher during the initial stages of gonadal development, than that of spermiation or ovulation stage (Shahi et al., 2017) ${ }^{[64]}$. In the spotted snakehead, expression profile of kissl, kissrl and kissr 2 revealed sexual dimorphism depending on tissues, and insignificant correlation was observed by the authors between the expression of kiss 1 and its receptors in the brain (Bakshi and Umesh, 2019) ${ }^{[3]}$.

Expression profile has been demonstrated in a number of fish expressing only kiss 2 . In the grass pufferfish, kiss 2 and kissrl mRNAs were significantly elevated during the spawning period in the brain and pituitary of both sexes, indicating a strong positive correlation between the amounts of kiss2/kissrl and gnrhl mRNAs in the brain over the spawning season (Shahjahan et al., 2010) ${ }^{[66]}$. In the orange spotted 
grouper exhibiting protogynous hermaphroditism, kiss 2 expression was higher in females compared to males, and in the first week after methyl-testosterone implantation, transcript levels of kiss 2 and kissrl in the hypothalamus reduced significantly. Interestingly, kiss2 expression increased on the fourth week, in accordance with the expression pattern of gnrhl mRNA in the hypothalamus suggesting involvement of kisspeptin system in the sex reversal in orange spotted grouper (Shi et al., 2010) ${ }^{[68]}$. In female Senegalese sole (Solea senegalensis), Mechaly et al. (2012) found highest kiss 2 mRNA expression in the forebrain and midbrain either before or during the spawning season. In the Atlantic cod, elevation in kiss 2 in vitellogenic females and spermiating males and spikes in kissr4 during early vitellogenesis in females and spermatogenesis in males was observed (Cowan et al., 2012) ${ }^{\text {[7] }}$. Administration of thyroid hormone significantly increases kiss 2 and gnrh1 mRNAs in the sexually mature males of Nile tilapia (Ogawa et al., 2013) [42]. The kiss 2 mRNA in male seahorse brain increased significantly at the early pubertal stage, and decreased significantly during pregnancy (Zhang et al., 2018) ${ }^{[81]}$. Both kiss 2 and kissr are highly expressed in the brain regions of sexually mature black porgy (Ma et al., 2019) ${ }^{[31]}$. At the onset of sexual maturation in the threespine stickleback, kiss 2 and kissr mRNA levels were higher, suggesting their possible involvement in pubertal onset (Shao et al., 2019) [67]. Likewise, changes in expression patterns of kiss 2 mRNA during different developmental stages indicated its potential role in embryonic development of singhi, a freshwater catfish of India (Kumari et al., 2020) ${ }^{[28] .}$

\section{Functional Kisspeptin Peptides in Teleost Fish}

Based on the position of dibasic amino acid residues, upstream to kisspeptin-10 regions, Kiss1-10 and Kiss2-10 of teleosts are suggested to produce Kiss1 pentadecapeptides (Kiss1-15) and Kiss2 dodecapeptides (Kiss2-12), respectively (Table 1 and Table 2). However, differences have been noted in the position of dibasic amino acid residues, upstream to kisspeptin-10 regions in few species. Dibasic amino acid residues (KR) have been found five position upstream to Kiss1-10 in medaka (Kitahashi et al., 2009) ${ }^{[26], ~ z e b r a f i s h ~}$ (Kitahashi et al., 2009) ${ }^{[26]}$ European seabass (Felip et al., 2009) ${ }^{[12]}$, chub mackerel (Selvaraj et al., 2010) ${ }^{[58], ~ g o l d f i s h ~}$ (Li et al., 2009) [30], striped bass (Zmora et al., 2012) ${ }^{[83]}$,

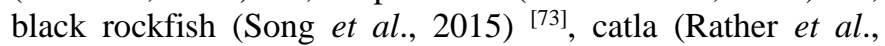
2016) ${ }^{[55]}$, rohu (Saha et al., 2016) ${ }^{[56]}$, golden mahseer (Shahi et al., 2017) ${ }^{[64]}$, pejerrey (Bohórquez et al., 2017) ${ }^{[5]}$ and Atlantic bluefin tuna (Ohga et al., 2020) [48], suggesting pyroglutamated Kiss1 pentadecapeptide as mature form in these fish. In chub mackerel and grouper species, it is likely that Kiss1 hexadecapeptides are mature forms, based on the position of dibasic amino acid residues (Kang et al., 2012; Ohga et al., 2013) ${ }^{[22,47]}$. Interestingly, in the chub mackerel reporter gene assays have indicated higher potency for receptor activation of Kiss1-16 peptides compared to Kiss115 and pyroglutamated Kiss1-15 peptides (Ohga et al., 2017) [44]. Also, Ohga et al. (2020) performed alanine scanning of Kiss1-15 peptides of chub mackerel, and highlighted the importance of specific residues in receptor binding. Surprisingly, the study found that primary structure of the functional peptide might be species-specific even within species of the family Scombridae, and demonstrated five types of putative mature Kiss1 peptides from sixteen scombridae species (Table 1).

In contrast to Kiss1, dibasic residues (RR) have been found two positions upstream to Kiss2-10 region in zebrafish (Kitahashi et al., 2009 ) [26], medaka (Kitahashi et al., 2009) ${ }^{[26]}$, European seabass (Felip et al., 2009) ${ }^{[12]}$, orange spotted grouper (Shi et al., 2010) ${ }^{[68]}$, chub mackerel (Selvaraj et al., 2010) ${ }^{[58]}$, red seabream (Shimizu et al., 2012) ${ }^{[69]}$, Atlantic

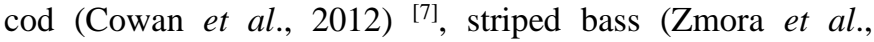
$2012)^{[83]}$, Nile tilapia (Ogawa et al., 2013) ${ }^{[42]}$, grass pufferfish (Shahjahan et al., 2010) [66], catla (Rather et al., 2016) ${ }^{[55],}$ rohu (Saha et al., 2016) ${ }^{[56]}$, pejerrey (Bohórquez et al., 2017) ${ }^{[5]}$, golden mahseer (Shahi et al., 2017) ${ }^{[64]}$, seahorse (Zhang et al., 2018) ${ }^{[81]}$ and black porgy (Ma et al., 2019) ${ }^{[31]}$, suggesting Kiss2 dodecapeptide as mature form in these species. However, in the salmon immunoaffinity purification and mass spectrometric analysis have indicated mature peptide of kiss 2 gene as tridecapeptide (Osugi et al., 2013) ${ }^{[50]}$ (Table 2). Recently, putative mature form of Kiss 2 was confirmed to be Kiss 2 dodecapeptide in sixteen species of family scombridae (Ohga et al., 2020) ${ }^{[48]}$.

Surprisingly, dibasic amino acid residues are located five and six positions upstream to Kiss2-10 in few species (Table 3). In zebrafish, goldfish, catla, rohu, golden mahseer, singhi and Chinese rare minnow, dibasic residues are located five position upstream to Kiss2-10 region, suggesting possibility of Kiss2 pentadecapeptide (Kiss2-15) as mature form in these species (Kitahashi et al., 2009; Li et al., 2009; Rather et al., 2016; Saha et al., 2016; Shahi et al., 2017; Kumari et al., 2020) $[26,30,55,56,64,28]$. In the rainbow trout, dibasic amino acid residues are found six position upstream to Kiss2-10 region, indicating possibility of Kiss2 hexadecapeptide as mature form (Genbank Accession No. JX122506).

Table 1: Kiss1 pentadecapeptides/hexadecapeptides in teleost fish

\begin{tabular}{|c|c|c|c|c|c|c|c|c|c|c|c|c|c|c|c|}
\hline 1 & 2 & 3 & 4 & 5 & 6 & 7 & 8 & 9 & 10 & 11 & 12 & 13 & 14 & 15 & 16 \\
\hline \multicolumn{16}{|c|}{ Zebrafish, Goldfish, Catla, Rohu, Golden mahseer } \\
\hline- & Gln & Asn & Val & Ala & Tyr & Tyr & Asn & Leu & Asn & Ser & Phe & Gly & Leu & Arg & Tyr \\
\hline \multicolumn{16}{|c|}{ Goldfish } \\
\hline- & Gln & Lys & Val & Ala & Tyr & Tyr & Asn & Leu & Asn & Ser & Phe & Gly & Leu & Arg & Tyr \\
\hline \multicolumn{16}{|c|}{ Medaka } \\
\hline- & Gln & Asp & Leu & Ser & Ser & Tyr & Asn & Leu & Asn & Ser & Phe & Gly & Leu & Arg & Tyr \\
\hline \multicolumn{16}{|c|}{ European seabass, Striped bass, Black rockfish, Pejerrey } \\
\hline- & Gln & Asp & Val & Ser & Ser & Tyr & Asn & Leu & Asn & Ser & Phe & Gly & Leu & Arg & Tyr \\
\hline \multicolumn{16}{|c|}{ Atlantic Bluefin tuna } \\
\hline- & Gln & Asp & Met & Ser & Ser & Tyr & Asn & Phe & Asn & Ser & Phe & Gly & Leu & Arg & Tyr \\
\hline \multicolumn{16}{|c|}{ Chub Mackerel } \\
\hline His & Gln & Asp & Met & Ser & Ser & Tyr & Asn & Phe & Asn & Ser & Phe & Gly & Leu & Arg & Tyr \\
\hline \multicolumn{16}{|c|}{ Longtooth grouper } \\
\hline His & Gln & Asp & Val & Ser & Ser & Tyr & Asn & Leu & Asn & Ser & Phe & Gly & Leu & Arg & Tyr \\
\hline
\end{tabular}


Table 2: Kiss 2 dodecapeptides/tridecapeptides in teleost fish

\begin{tabular}{|c|c|c|c|c|c|c|c|c|c|c|c|c|}
\hline 1 & 2 & 3 & 4 & 5 & 6 & 7 & 8 & 9 & 10 & 11 & 12 & 13 \\
\hline \multicolumn{13}{|c|}{ Zebrafish, Medaka, Catla, Rohu, Golden mahseer, Pejerrey, Singhi } \\
\hline- & Ser & Lys & Phe & Asn & Tyr & Asn & Pro & Phe & Gly & Leu & Arg & Phe \\
\hline \multicolumn{13}{|c|}{ Chub Mackerel } \\
\hline- & Ser & Asn & Phe & Asn & Phe & Asn & Pro & Phe & Gly & Leu & Arg & Phe \\
\hline \multicolumn{13}{|c|}{ Orange spotted grouper, European seabass, Striped bass, Grass Puffer, Senegalese sole, Red seabream, Black porgy, Atlantic bluefin tuna } \\
\hline- & Ser & Lys & Phe & Asn & Phe & Asn & Pro & Phe & Gly & Leu & Arg & Phe \\
\hline \multicolumn{13}{|c|}{ Goldfish } \\
\hline- & Gly & Lys & Phe & Asn & Tyr & Asn & Pro & Phe & Gly & Leu & Arg & Phe \\
\hline \multicolumn{13}{|c|}{ Nile tilapia } \\
\hline- & Ser & Asn & Phe & Asn & Tyr & Asn & Pro & Leu & Ser & Leu & Arg & Phe \\
\hline \multicolumn{13}{|c|}{ Atlantic bluefin tuna } \\
\hline- & Ser & Lys & Phe & Asn & Phe & Asn & Pro & Phe & Gly & Leu & Arg & Phe \\
\hline \multicolumn{13}{|c|}{ Grass pufferfish } \\
\hline- & Ser & Lys & Phe & Asn & Leu & Asn & Pro & Phe & Gly & Leu & Arg & Phe \\
\hline \multicolumn{13}{|c|}{ Seahorse } \\
\hline- & Asn & Lys & Phe & Asn & Val & Asn & Pro & Phe & Gly & Leu & Arg & Phe \\
\hline \multicolumn{13}{|c|}{ Atlantic cod } \\
\hline- & Ser & Pro & Phe & Asn & Tyr & Asn & Pro & Phe & Gly & Leu & Arg & Phe \\
\hline \multicolumn{13}{|c|}{ Masu salmon, Kokanee salmon } \\
\hline Thr & Ser & Lys & Phe & Asn & Phe & Asn & Pro & Phe & Gly & Leu & Arg & Phe \\
\hline
\end{tabular}

Table 3: Possibility of Kiss2 pentadecapeptides/hexadecapeptides in teleost fish

\begin{tabular}{|l|c|c|c|c|c|c|c|c|c|c|c|c|c|c|c|c|}
\hline $\mathbf{1}$ & $\mathbf{2}$ & $\mathbf{3}$ & $\mathbf{4}$ & $\mathbf{5}$ & $\mathbf{6}$ & $\mathbf{7}$ & $\mathbf{8}$ & $\mathbf{9}$ & $\mathbf{1 0}$ & $\mathbf{1 1}$ & $\mathbf{1 2}$ & $\mathbf{1 3}$ & $\mathbf{1 4}$ & $\mathbf{1 5}$ & $\mathbf{1 6}$ \\
\hline \multicolumn{8}{|c|}{ Zebrafish } \\
\hline & Leu & Ala & Arg & Ser & Lys & Phe & Asn & Tyr & Asn & Pro & Phe & Gly & Leu & Arg & Phe \\
\hline & \multicolumn{8}{|c|}{ Goldfish } \\
\hline & Leu & Pro & Arg & Gly & Lys & Phe & Asn & Tyr & Asn & Pro & Phe & Gly & Leu & Arg & Phe \\
\hline
\end{tabular}

\subsection{Short-term effects of kisspeptin peptides on gene expression}

Several studies have demonstrated that administration of kisspeptin peptide through different routes induce changes in the elements of reproductive axis. Filby et al. (2008) found that intraperitoneal administration of mammalian kisspeptin10 at a dose of $2 \mathrm{nmol} / \mathrm{g}$ body weight in early-mid pubertal fish induces grnh3 and kiss $1 r$ expression in the brain after 10 hour post-injection. Intramuscular administration of seabass Kiss1-10 and Kiss2-10 at a dose of $250 \mathrm{ng} / \mathrm{g}$ body weight in prepubertal seabass evoked significant elevations in circulating LH levels at 120 min. after injection, with Kiss110 and Kiss2-10 eliciting 2 fold increase and 4 fold increase, respectively. Similarly, intramuscular administration of seabass Kiss1-10 and Kiss2-10 at a dose of $250 \mathrm{ng} / \mathrm{g}$ body weight revealed that only Kiss2-10 induces an increase of circulating LH levels at 120 minute after injection (Felip et al., 2009) ${ }^{[12]}$. In zebrafish, intraperitoneal administration of Kiss1-10 and Kiss2-10 at a dose of $2 \mathrm{nmol} / \mathrm{g}$ body weight to sexually mature females showed that Kiss2-10 induces significant increase in pituitary $f \operatorname{sh} \beta$ ( 2.7 fold $)$ and $\ln \beta$ ( 8 fold $)$ (Kitahashi et al., 2009) ${ }^{[26]}$. Incubation of primary cultures of goldfish pituitary cells with goldfish Kiss1-10 (100 nM) induced an increase in luteinizing hormone (LH), growth hormone $(\mathrm{GH})$ and prolactin (PRL) in $30 \mathrm{~min}$. duration; shortterm incubation with Kisspeptin-10 did not alter LH, GH and PRL mRNAs expression but elevation in mRNA level for the hormones were observed by prolonging the kisspeptin-10 treatment to $24 \mathrm{~h}$ (Yang et al., 2009) ${ }^{[79]}$. Li et al (2009) found that in-vitro action of goldfish Kiss1-10 and Kiss2-10 in primarily culture of pituitary cells did not stimulated LH release; however, intraperitoneal administration of Kiss1-10 significantly increased serum LH levels in a dose-dependent manner $(0.01-1 \mu \mathrm{g} / \mathrm{g})$. In orange spotted grouper, intraperitoneal administration of Kiss2-10 at a dose of 2 $\mathrm{nmol} / \mathrm{g}$ body weight significantly increases gnrhl mRNA levels in the hypothalamus, and $f s h \beta$ mRNA levels in the pituitary at 6 and $12 \mathrm{~h}$ post-injection (Shi et al., 2010) ${ }^{[68]}$. Intramuscular administration of Kiss1-15 and Kiss2-12 were potent in inducing the pituitary LH release in striped bass; however, the responses showed dose-dependent and reproductive stage differences. In prepubertal fish, only Kiss2-12 increased LH levels by 4.5-7 fold at doses of 5 and $25 \mathrm{nmol} / \mathrm{kg}$ body weight, while $100 \mathrm{nmol} / \mathrm{kg}$ body weight induced LH blood levels by only 2.5 and 3.5 fold at $4 \mathrm{~h}$ and $24 \mathrm{~h}$ post-injection, respectively. In adult fish of midgonadal development phase, the response was less prominent compared to prepubertal fish. Kiss1-15 at doses of 50 and 100 $\mathrm{nmol} / \mathrm{kg}$ body weight induced LH plasma levels by 1.7 and 2.5 fold at 24 h post-injection; Kiss2-12 at doses of 5 and 25 $\mathrm{nmol} / \mathrm{kg}$ body weight increased LH levels significantly at $24 \mathrm{~h}$ post-injection (Zmora et al., 2012) ${ }^{[83]}$. In chub mackerel, intracebroventricular administration of synthetic chub mackerel Kiss1-15 and Kiss1-12 peptides showed that in female fish, gnrhl levels decreased in the presence of both kisspeptin peptides at $12 \mathrm{~h}$ postinjection; only Kiss2-12 significantly increased $f \operatorname{sh} \beta$ and $\operatorname{lh} \beta$ mRNAs at $12 \mathrm{~h}$ postinjection (Ohga et al., 2014) ${ }^{[49]}$. In vitro studies using brain slices of striped bass demonstrated that only Kiss 2 can upregulate the expression of hypophysiotropic gnrhl, which was subsequently diminished by kisspeptin antagonists, pep 234 and pep 359 (Zmora et al., 2015) ${ }^{\text {[84] }}$. In the cinnamon 
clownfish, treatment with 0.1 and $0.5 \mu \mathrm{g} / \mathrm{g}$ body mass of mammalian kisspeptin-10 significantly increased the mRNA levels of growth hormone $(\mathrm{GH})$ in the pituitary. Similarly, under in vitro condition, treatment with Kiss significantly increased GH mRNA level, especially at $48 \mathrm{~h}$ after treatment (Kim et al., 2014, 2015) ${ }^{[24-25]}$. This studies suggested that kisspeptin plays a role in modulating growth and artificially induced rapid growth in cinnamon clownfish. Park et al. (2016) found that intraperitoneal administration of tilapia Kiss2-10 into immature male and female Nile tilapia at a dose of $200 \mathrm{pmol} / \mathrm{g}$ body weight increases the expression of gnrhl, $f s h \beta$, and $l h \beta$ mRNAs in the brain and increased estradiol-17 $\beta$ and 11-ketotestosterone levels in the blood plasma. In fish injected with Kiss2-10 twice weekly for a total of 8 times in Nile tilapia; fish at late vitellogenesis accounts for $30 \%$, while fish at pre-vitellogenesis only for $20 \%$, in the control group, fish at late vitellogenesis accounts for $16.6 \%$ and at previtellogenesis $25 \%$. Intraperitoneal injection of porgy Kiss210 stimulated gene expression of kissr, gnrh1, gnrh3, $f_{s h} \beta$, $\operatorname{lh} \beta, p 450 \mathrm{c} 17$, star, and ar, and the serum testosterone level in male black porgy (Ma et al., 2019) ${ }^{[31]}$. Nile tilapia pituitaries cultured with high concentration of Kiss2-10 more than 0.1 $\mu \mathrm{M}$ for 3 hours exhibited a significant increase of $f s h \beta$ mRNA expression, but not $\operatorname{lh} \beta$ mRNA; expression of both $f s h \beta$ and $\operatorname{lh} \beta$ mRNAs increased after 6 hours in $0.1 \mu \mathrm{M}$ of Kiss $2-10$ medium (Park et al., 2020) ${ }^{[53]}$. In goldfish, kisspeptins found to be a more suitable inducing hormone than $\mathrm{GnRH}$ based analogue, Ovaprim for accelerating and synchronizing oocyte maturation (Valipour et al., 2020) ${ }^{\text {[77] }}$. These studies clearly indicate that kisspeptin peptides can stimulate reproductive axis.

\subsection{Long-term effects of kisspeptin peptides on growth and maturation of gonads}

Repeated bi-weekly injections (over 7 weeks) of European sea bass Kiss1-10 and Kiss2-10 peptides (250 ng/g body weight) accelerated pubertal onset in basses of the genus Morone species; in sexually mature basses, an increase in gonadosomatic index value, and advancement in gonadal development was observed (Beck et al., 2012) ${ }^{[4]}$. Nocillado et al. (2013) showed that administration of yellowtail kingfish Kiss 1-10 and Kiss2-10 peptides in prepubertal fish during the breeding $(50 \mu \mathrm{g} / \mathrm{kg})$ and non-breeding season $(100 \mu \mathrm{g} / \mathrm{kg})$ showed that pituitary expression of $f \operatorname{sh} \beta$ and $\operatorname{lh} \beta$ was upregulated only with Kiss $1-10$ treatment regardless of the season; gonadal development was stimulated in male fish with either Kiss1-10 or Kiss2-10, with Kiss2-10 being more effective during the non-breeding period. In chub mackerel, continuous administration of synthetic chub mackerel Kiss115 using mini-osmotic pumps stimulated an increase in GSI values of adult male fish on day 45 post-injection; spermiating male fish showed significantly higher levels of pituitary $f s h \beta$ and $\operatorname{lh} \beta$ mRNAs and circulating 11ketotestosterone; yolk vesicles were observed in the oocytes of Kiss1-15 treated fish with higher levels of pituitary $f_{s h} \beta$ and circulating estradiol-17 (Selvaraj et al., 2013a) ${ }^{[60]}$. Similarly, subcutaneous administration of synthetic chub mackerel Kiss1-15 using injection for three times (biweekly) over 6 weeks, stimulated an increase in GSI values of prepubertal male fish on day 45 post-injection; testicular histology revealed higher percentage of advanced stages of germ cells in comparison to other treatments; levels of circulating sex steroids, 11-ketotestosterone and estradiol-17 $\beta$ were higher in Kiss1-15 treated fish (Selvaraj et al., 2013b)
[62]. Also, subcutaneous administration of synthetic chub mackerel Kiss1-15 using injection for three times (biweekly) over 6 weeks, stimulated an increase in the oocyte diameter of previtellogenic oocytes; testosterone and estradiol-17 $\beta$ levels were significantly higher in Kiss1-15 injected fish (Selvaraj et $a l ., 2015)^{[61]}$. These studies have demonstrated the potential of using synthetic kisspeptin peptides for inducing gonadal development at different reproductive stages.

\section{Conclusion}

Recent isolation of cDNAs encoding kisspeptins in different teleost fish has confirmed the presence of different mature peptides as previously demonstrated for mammalian kisspeptins. Reporter gene assays have demonstrated that shorter form of kisspeptin (Kiss-10) exhibit lower activity in activating kisspeptin receptors compared to larger forms (Kiss1-15, Kiss1-16, Kiss2-12), atleast in marine scombrids. Selection of suitable mature peptide would be important in inducing growth and maturation of fish gonads as shorter peptides would undergo faster clearance in peripheral circulation. In cyprinids like goldfish and Prussian carp, synthetic kisspeptin peptides have been shown to be superior than existing $\mathrm{GnRH}$ analogues, when administered along with dopamine antagonists. Recently, in marine scombrid fish, functional mature peptide of Kiss1 and Kiss2 has been demonstrated highlighting the importance of selection of suitable mature peptides in commercial aquaculture.

\section{References}

1. Akazome Y, Kanda S, Okubo K, Oka Y. Functional and evolutionary insights into vertebrate kisspeptin systems from studies of fish brain. J Fish Biol 2010;76:161-182.

2. Alvarado MV, Servili A, Molés G, Gueguen MM, Carrillo M, Kah $\mathrm{O}$ et al. Actions of sex steroids on kisspeptin expression and other reproduction-related genes in the brain of the teleost fish European sea bass. J. Exp. Biol 2016;219(Pt 21):3353-3365.

3. Bakshi A, Umesh R. Tissue-specific sexual dimorphism in the expression of kisspeptin and its receptors in spotted snakehead Channa punctatus. Current Sci 2019;116(5):802-810.

4. Beck BH, Fuller SA, Peatman E, McEntire ME, Darwish A, Freeman DW. Chronic exogenous kisspeptin administration accelerates gonadal development in basses of the genus Morone. Comp. Biochem. Physiol. Part A 2012;162:265-273.

5. Cao Y, Li Z, Jiang W, Ling Y, Kuang H. Reproductive functions of Kisspeptin/KISS1R Systems in the Periphery. Reprod. Biol. Endocrinol 2019;17:65.

6. Castellano JM, Roa J, Luque RM, Dieguez C, Aguilar E, Pinilla L et al. KiSS-1/kisspeptins and the metabolic control of reproduction: physiologic roles and putative physiopathological implications. Peptides 2009;30(1):139-145.

7. Cowan M, Davie A, Migaud H. Photoperiod effects on the expression of kisspeptin and gonadotropin genes in Atlantic cod, Gadus morhua, during first maturation. Comp. Biochem. Physiol. Part A Mol. Integr. Physiol. 2012;163:82-94.

8. Escobar S, Felip A, Gueguen MM, Zanuy S, Carrillo M, Kah O et al, Expression of kisspeptins in the brain and pituitary of the European sea bass (Dicentrarchus labrax). J. Comp. Neurol 2013;521(4):933-948.

9. Escobar S, Servili A, Espigares F, Gueguen MM, Brocal 
I, Felip A et al. Expression of kisspeptins and kiss receptors suggests a large range of functions for kisspeptin systems in the brain of the European sea bass. PLoS One 2013;8(7):e70177.

10. Espigares F, Carrillo M, Gómez A, Zanuy S. The forebrain-midbrain acts as functional endocrine signaling pathway of Kiss2/Gnrh1 system controlling the gonadotroph activity in the teleost fish European sea bass (Dicentrarchus labrax). Biol. Reprod 2015;92(3):70.

11. Espigares F, Zanuy S, Gómez A, Kiss2 as a regulator of Lh and Fsh secretion via paracrine/autocrine signaling in the teleost fish European seabass (Dicentrarchus labrax). Biol. Reprod 2015;93(5):114.

12. Felip A, Zanuy S, Pineda R, Pinilla L, Carrillo M, TenaSempere M, et al. Evidence for two distinct KiSS genes in non-placental vertebrates that encode kisspeptins with different gonadotropin-releasing activities in fish and mammals. Mol. Cell. Endocrinol 2009;312:61-71.

13. Feng T, Bai JH, Xu XL, Liu Y. Kisspeptin and its effect on mammalian spermatogenesis. Curr. Drug Metab. 2019;20(1):9-14.

14. Filby AL, van Aerle R, Duitman JW, Tyler CR. The kisspeptin/gonadotropin-releasing hormone pathway and molecular signaling of puberty in fish. Biol. Reprod. 2008;78:278-289.

15. Gosiewski G, Sokolowska-Mikolajczyk M, Chyb J, Socha M. Preliminary results concerning the influence of human kisspeptin on LH secretion in Prussian carp (Carassius gibelio) females at the stage of ovarian recrudescence and spawning season. Folia Biologica (Krakow) 2015;63(1):25-33.

16. Gottsch ML, Cunningham MJ, Smith JT, Popa SM, Acohido BV, Crowley WF et al. A role for kisspeptins in the regulation of gonadotropin secretion in the mouse. Endocrinology 2004;145(9):4073-4077.

17. Kah O, Lethimonier C, Somoza G, Guilgur LG, Vaillant C, Lareyre JJ. GnRH and GnRH receptors in metazoa: A historical, comparative, and evolutive perspective. Gen. Comp. Endocrinol 2007; 153:346-364.

18. Kanda S, Akazome $\mathrm{Y}$, Matsunaga $\mathrm{T}$, Yamamoto $\mathrm{N}$, Yamada S, Tsukamura $\mathrm{H}$ et al. Identification of KiSS-1 product kisspeptin and steroid-sensitive sexually dimorphic kisspeptin neurons in medaka (Oryzias latipes). Endocrinology 2008;149:2467-2476.

19. Kanda S, Akazome Y, Mitani Y, Okubo K, Oka Y. Neuroanatomical evidence that kisspeptin directly regulates isotocin and vasotocin neurons. PLoS One. 2013;8(4):e62776.

20. Kanda S, Karigo T, Oka Y. Steroid sensitive kiss2 neurones in the goldfish: evolutionary insights into the duplicate kisspeptin gene-expressing neurones. J. Neuroendocrinol 2012;24(6):897-906.

21. Kanda S, Oka Y. Evolutionary insights into the steroid sensitive kiss1 and kiss2 neurons in the vertebrate brain. Frontiers in endocrinology 2012;3:28.

22. Kang H-C, Lee C-H, Song Y-B, Baek H-J, Kim H-B, Lee Y-D. KiSS1, KiSS2, GPR54 mRNA expression of the blacktip grouper Epinephelus fasciatus. Dev. Reprod. 2012;16(2):121-128.

23. Kauffman AS, Clifton DK, Steiner RA. Emerging ideas about kisspeptin-GPR54 signaling in the neuroendocrine regulation of reproduction. Trends Neurosci 2007;30:504-511.

24. Kim NN, Choi YU, Park HS, Choi CY. Kisspeptin regulates the somatic growth-related factors of the cinnamon clownfish Amphiprion melanopus. Comp. Biochem. Physiol. A Mol. Integr. Physiol 2015;179:1724.

25. Kim NN, Shin HS, Choi YJ, Choi CY. Kisspeptin regulates the hypothalamus-pituitary-gonad axis gene expression during sexual maturation in the cinnamon clownfish, Amphiprion melanopus. Comp. Biochem. Physiol. B Biochem. Mol. Biol 2014;168:19-32.

26. Kitahashi T, Ogawa S, Parhar IS. Cloning and expression of kiss2 in the Zebrafish and Medaka. Endocrinology 2009;150:821-831.

27. Kotani M, Detheux M, Vandenbogaerde A, Communi D, Vanderwinden JM, Le Poul E et al. The metastasis suppressor gene KiSS-1 encodes kisspeptins, the natural ligands of the orphan G protein-coupled receptor GPR54. J. Biol. Chem 2001;276:34631-34636.

28. Kumari P, Kumar M, Sehgal N, Aggarwal N. In silico analysis of kiss2, expression studies and protein-protein interaction with gonadotropin-releasing hormone 2 (GnRH2) and luteinizing hormone beta (LH $\beta)$ in Heteropneustes fossilis. J. Biomol. Struct. Dyn 2020;21:1-15.

29. Lee YR, Tsunekawa K, Moon MJ, Um HN, Hwang JI, Osugi T et al. Molecular evolution of multiple forms of kisspeptins and GPR54 receptors in vertebrates. Endocrinology 2009;150(6):2837-2846.

30. Li S, Zhang Y, Liu Y, Huang X, Huang W, Lu D, et al Structural and functional multiplicity of the kisspeptin/GPR54 system in goldfish (Carassius auratus). J. Endocrinol 2009;201:407-418.

31. Ma XL, Yuan BL, Zhou LB. The Kiss2/GPR54 system stimulates the reproductive axis in male black porgy, Acanthopagrus schlegelii. Gen. Comp. Endocrinol 2019;280:158-167.

32. Matsuyama $M$, Selvaraj $S$, Nyuji $M$, Ohga $H$. Involvement of brain-pituitary-gonadal axis on regulation of reproductive cycle in female chub mackerel. In Sexual Plasticity and Gametogenesis in Fishes, Nova Science Publishers Inc. 2013, 251-273,

33. Matsuyama M, Shiraishi T, Sundaray JK, Rahman A, Ohta K, Yamaguchi A. Steroidogenesis in ovarian follicles of chub mackerel, Scomber japonicus. Zool. Sci. 2005;22(1):101-110.

34. Mechaly AS, Viñas J, Piferrer F. Identification of two isoforms of the Kisspeptin-1 receptor (kiss1r) generated by alternative splicing in a modern teleost, the Senegalese sole (Solea senegalensis). Biol. Reprod 2009;80:60-69.

35. Mechaly AS, Viñas J, Piferrer F. Gene structure analysis of kisspeptin-2 (Kiss2) in the Senegalese sole (Solea senegalensis): characterization of two splice variants of Kiss2, and novel evidence for metabolic regulation of kisspeptin signaling in nonmammalian species, Mol. Cell. Endocrinol 2011;339:14-24.

36. Mechaly AS, Viñas J, Piferrer F. Sex-specific changes in the expression of kisspeptin, kisspeptin receptor, gonadotropins and gonadotropins receptors in the Senegalese sole (Solea senegalensis) during a full reproductive cycle. Comp. Biochem. Physiol. Part A Mol. Integr. Physiol 2012;162:364-371.

37. Mechaly AS, Viñas J, Piferrer F. The kisspeptin system genes in teleost fish, their structure and regulation, with particular attention to the situation in Pleuronectiformes. Gen. Comp. Endocrinol 2013;188:258-68. 
38. Mitani Y, Kanda S, Akazome Y, Zempo B, Oka Y. Hypothalamic Kiss1 but not Kiss2 neurons are involved in estrogen feedback in medaka (Oryzias latipes). Endocrinology 2010;151:1751-1759.

39. Mohammadzadeh M, Moradian F, Yeganeh S, Falahatkar B, Milla S. Design, production and purification of a novel recombinant gonadotropin-releasing hormone associated peptide as a spawning inducing agent for fish. Prot. Express. Purif. 2020;166:105510.

40. Nagler J, Cavileer T, Caldwell L, Schultz I. Duplication of the Kisspeptin-2 gene in rainbow trout (Oncorhynchus mykiss) brain and pituitary. Biol. Reprod 2011;85(1):814.

41. Nocillado JN, Zohar Y, Biran J, Levavi-Sivan B, Elizur A. Chronic kisspeptin administration stimulated gonadal development in pre-pubertal male yellowtail kingfish (Seriola lalandi; Perciformes) during the breeding and non-breeding season. Gen. Comp. Endocrinol 2013;191:168-176.

42. Ogawa S, Ng KW, Xue X, Ramadasan PN, Sivalingam M, Li S, Levavi-Sivan B et al. Thyroid hormone upregulates hypothalamic kiss 2 gene in the male Nile tilapia, Oreochromis niloticus. Front. Endocrinol., 4, 184.

43. Ogawa, S., Parhar, I.S., 2013. Anatomy of the kisspeptin systems in teleosts. Gen. Comp. Endocrinol 2013;181:169-74.

44. Ohga H, Adachi H, Kitano H, Yamaguchi A, Matsuyama M. Kiss1 hexadecapeptide directly regulates gonadotropin-releasing hormone 1 in the scombroid fish, chub mackerel 2017;96(2):376-388.

45. Ohga H, Adachi H, Matsumori K, Kodama R, Nyuji M, Selvaraj S, et al. mRNA levels of kisspeptins, kisspeptin receptors, and GnRH1 in the brain of chub mackerel during puberty. Comp. Biochem. Physiol. A Mol. Integr. Physiol. 2015;179:104-112.

46. Ohga H, Akase F, Sakanoue R, Matsushima A, Ohta K, Matsuyama M. Alanine scanning and characterization of core peptides in Scombridae fish family for construction of Kiss1 super analog. Gen. Comp. Endocrinol. 2020;288:113356.

47. Ohga H, Fujinaga Y, Selvaraj S, Kitano H, Nyuji M, Yamaguchi A, et al. Identification, characterization, and expression profiles of two subtypes of kisspeptin receptors in a scombroid fish (chub mackerel). Gen. Comp. Endocrinol 2013;193:130-140.

48. Ohga H, Sakanoue R, Ohta K, Matsuyama M. Molecular characterization of kisspeptin 2 dodecapeptide in sixteen species of Scombridae. Fish. Sci. 2020;86:437-444.

49. Ohga H, Selvaraj S, Adachi H, Imanaga Y, Nyuji M, Yamaguchi A et al. Functional analysis of kisspeptin peptides in adult immature chub mackerel (Scomber japonicus) using an intracerebroventricular administration method. Neurosci. Lett. 2014;561:203207.

50. Ohga H, Selvaraj S, Matsuyama M. The roles of kisspeptin system in the reproductive physiology of fish with special reference to chub mackerel studies as main axis. Front. Endocrinol 2018;9:147.

51. Ohga H, Selvaraj S, Yamaguchi A, Matsuyama M. A unique expression profile of kisspeptin receptor genes during final oocyte maturation in female chub mackerel, Scomber japonicus. J Fac. Agri. Kyushu Univ. 2017;62(1):87-91.

52. Park JW, Jin YH, Oh SY, Kwon JY. Kisspeptin2 stimulates the HPG axis in immature Nile tilapia
(Oreochromis niloticus). Comp. Biochem. Physiol. B Biochem. Mol. Biol 2016;202:31-38.

53. Park JW, Kim JH, Kwon JY. Effects of Kiss2 on the expression of gonadotropin genes in the pituitary of Nile tilapia (Oreochromis niloticus). Dev. Reprod 2020;24(3):149-158.

54. Pasquier J, Kamech N, Lafont A, Vaudry H, Rousseau K, Dufour S. Molecular evolution of GPCRs: Kisspeptin/kisspeptin receptors, J Mol. Endocrinol 2014;52(3):T101-T117.

55. Rather MA, Bhat IA, Gireesh-Babu P, Chaudhari A, Sundaray JK, Sharma R. Molecular characterization of kisspeptin gene and effect of nano-encapsulted kisspeptin-10 on reproductive maturation in Catla catla. Domest. Anim. Endocrinol 2016;56:36-47.

56. Saha A, Pradhan A, Sengupta S, Nayak M, Samanta M, Sahoo L et al. Molecular characterization of two kiss genes and their expression in rohu (Labeo rohita) during annual reproductive cycle. Comp. Biochem. Physiol. B Biochem. Mol. Biol 2016;191:135-145.

57. Selvaraj S, Kitano H, Amano M, Ohga H, Yoneda M, Yamaguchi A, et al. Increased expression of kisspeptin and GnRH forms in the brain of scombroid fish during final ovarian maturation and ovulation. Reprod. Biol. Endocrinol. 2012;10:64.

58. Selvaraj S, Kitano H, Fujinaga Y, Ohga H, Yoneda M, Yamaguchi A, et al. Molecular characterization, tissue distribution, and mRNA expression profiles of two Kiss genes in the adult male and female chub mackerel (Scomber japonicus) during different gonadal stages. Gen. Comp. Endocrinol. 2010;169(1):28-38.

59. Selvaraj S, Kitano H, Ohga H, Yamaguchi A, Matsuyama M. Expression changes of mRNAs encoding kisspeptins and their receptors and gonadotropin-releasing hormones during early development and gonadal sex differentiation periods in the brain of chub mackerel (Scomber japonicus). Gen. Comp. Endocrinol 2015;222:20-32.

60. Selvaraj S, Ohga H, Kitano H, Nyuji M, Yamaguchi A, Matsuyama M. Peripheral administration of Kiss1 pentadecapeptideinduces gonadal development in sexually immature adult scombroidfish. Zool. Sci. 2013a;30(6):446-454.

61. Selvaraj S, Ohga H, Nyuji M, Kitano H, Nagano N, Yamaguchi A et al. Effects of synthetic kisspeptin peptides and GnRH analogue on oocyte growth and circulating sex steroids in prepubertal female chub mackerel (Scomber japonicus). Aqua. Res 2015;46:18661877.

62. Selvaraj S, Ohga H, Nyuji M, Kitano H, Nagano N, Yamaguchi A, et al. Subcutaneous administration of Kiss 1 pentadecapeptide accelerates spermatogenesis in prepubertal male chub mackerel (Scomber japonicus). Comp. Biochem. Physiol. Part A 2013b;166(2):228-236.

63. Servili A, Le Page Y, Leprince J, Caraty A, Escobar S, Parhar IS, et al. Organization of two independent kisspeptin systems derived from evolutionary-ancient kiss genes in the brain of zebrafish. Endocrinology 2011;152(4):1527-1540.

64. Shahi N, Singh AK, Sahoo M, Mallik SK, Thakuria D. Molecular cloning, characterization and expression profile of kisspeptin1 and kisspeptin1 receptor at brainpituitary-gonad (BPG) axis of golden mahseer, Tor putitora (Hamilton, 1822) during gonadal development. Comp. Biochem. Physiol. B Biochem. Mol. Biol. 
2017;205:13-29.

65. Shahjahan M, Kitahashi T, Ogawa S, Parhar IS. Temperature differentially regulates the two kisspeptin systems in the brain of zebrafish. Gen. Comp. Endocrinol 2013;193:79-85.

66. Shahjahan M, Motohashi E, Doi H, Ando H. Elevation of Kiss2 and its receptor gene expression in the brain and pituitary of grass puffer during the spawning season. Gen. Comp. Endocrinol. 2010;169(1):48-57.

67. Shao YT, Roufidou C, Chung PC, Borg B. Changes in kisspeptin, GnRH, and gonadotropin mRNA levels in male threespine stickleback (Gasterosteus aculeatus) photoperiod-induced sexual maturation. Evol. Ecol. Res. 2019;20(3):317-329.

68. Shi Y, Zhang Y, Li S, Liu Q, Lu D, Liu M et al. Molecular identification of the Kiss2/Kiss1ra system and its potential function during 17alpha-methyltestosteroneinduced sex reversal in the orange-spotted grouper, Epinephelus coioides. Biol. Reprod. 2010;83(1):63-74.

69. Shimizu Y, Tomikawa J, Hirano K, Nanikawa Y, Akazome Y, Kanda S et al. Central distribution of kiss2 neurons and peri-pubertal changes in their expression in the brain of male and female red seabream Pagrus major. Gen. Comp. Endocrinol 2012;175(3):432-442.

70. Sokolowska-Mikolajczyk M, Gosiewski G, Chyb J, Socha M. Short-term effects of human kisspeptin on LH secretion in Prussian carp (Carassius gibelio Bloch, 1782) females at two gonad maturity stages. Turkish J. Fish. Aquat. Sci. 2018;18:229-237.

71. Sokolowska-Mikolajczyk M, Gosiewski G, Chyb J, Socha M. Interaction between kisspeptin and dopamine in the regulation of in vitro LH release in Prussian carp (Carassius gibelio Bloch, 1782) females at the time of gonad recrudescence and spawning period. Turkish J Fish. Aquat. Sci. 2020;20:359-366.

72. Somoza GM, Mechaly AS, Trudeau VL. Kisspeptin and $\mathrm{GnRH}$ interactions in the reproductive brain of teleosts. Gen. Comp. Endocrinol. 2020;298, 113568.

73. Song H, He Y, Ma L, Zhou X, Liu X, Qi J, Zhang Q Characterisation of kisspeptin system genes in an ovoviviparous teleost: Sebastes schlegeli. Gen. Comp. Endocrinol. 2015;214:114-25.

74. Suzuki H, Kazeto Y, Gen K, Ozaki Y. Functional analysis of recombinant single-chain Japanese eel Fsh and Lh produced in FreeStyle 293-F cell lines: Binding specificities to their receptors and differential efficacy on testicular steroidogenesis. Gen. Comp. Endocrinol 2020;285:113241.

75. Tovar Bohórquez MO, Mechaly AS, Hughes LC, Campanella D, Ortí G, Canosa LF et al. Kisspeptin system in pejerrey fish (Odontesthes bonariensis). Characterization and gene expression pattern during early developmental stages. Comp. Biochem. Physiol. A Mol. Integr. Physiol 2017;204:146-156.

76. Um HN, Han JM, Hwang JI, Hong SI, Vaudry H, Seong JY. Molecular coevolution of kisspeptins and their receptors from fish to mammals. Ann. N. Y. Acad. Sci. 2010;1200:67-74.

77. Valipour A, Heidari SB, Asghari M, Balalaie S, Rabouti $\mathrm{H}$, Omidian N. The effect of different exogenous kisspeptins on sex hormones and reproductive indices of the goldfish (Carassius auratus) broodstock. J. Fish Biol. 2020;98(4):1137-1143.

78. Wang Q, Sham KW, Ogawa S, Li S, Parhar IS, Cheng
$\mathrm{CH}$ et al. Regulation of the two kiss promoters in goldfish (Carassius auratus) by estrogen via different ER $\alpha$ pathways. Mol. Cell. Endocrinol. 2013;375(1, 2):130-139.

79. Yang B, Jiang Q, Chan T, Ko KWW, Wong AOL. Goldfish kisspeptin: Molecular cloning, tissue distribution of transcript expression, and stimulatory effects on prolactin, growth hormone and luteinizing hormone secretion and gene expression via direct actions at the pituitary level. Gen. Comp. Endocrinol 2010;165:60-71.

80. Yaron Z, Gur G, Melamed P, Rosenfeld H, Elizur A, Levavi-Sivan B. Regulation of fish gonadotorpins. Internl. Rev. of Cytol. 2003;225:131-185.

81. Zhang H, Zhang B, Qin G, Li S, Lin Q. The roles of the kisspeptin system in the reproductive physiology of the lined seahorse (Hippocampus erectus), an ovoviviparous fish with male pregnancy. Front. Neurosci 2018;12:940.

82. Zhao Y, Lin MC, Mock A, Yang M, Wayne NL. Kisspeptins modulate the biology of multiple populations of gonadotropin-releasing hormone neurons during embryogenesis and adulthood in zebrafish (Danio rerio). PLoS One 2014;9(8):e104330.

83. Zmora N, Stubblefield J, Zulperi Z, Biran J, LevaviSivan B, Muñoz-Cueto JA et al. Differential and gonad stage-dependent roles of kisspeptin1 and kisspeptin2 in reproduction in the modern teleosts Morone species. Biol. Reprod 2012;86:177.

84. Zmora N, Stubblefield JD, Wong TT, Levavi-Sivan B, Millar RP, Zohar Y. Kisspeptin antagonists reveal kisspeptin 1 and kisspeptin 2 differential regulation of reproduction in the teleost, Morone saxatilis. Biol. Reprod 2015;93(3):76. 